\title{
Canto para Hildegard
}

\author{
Ricardo Henrique Serrão
}

Universidade Estadual de São Paulo | Brasil

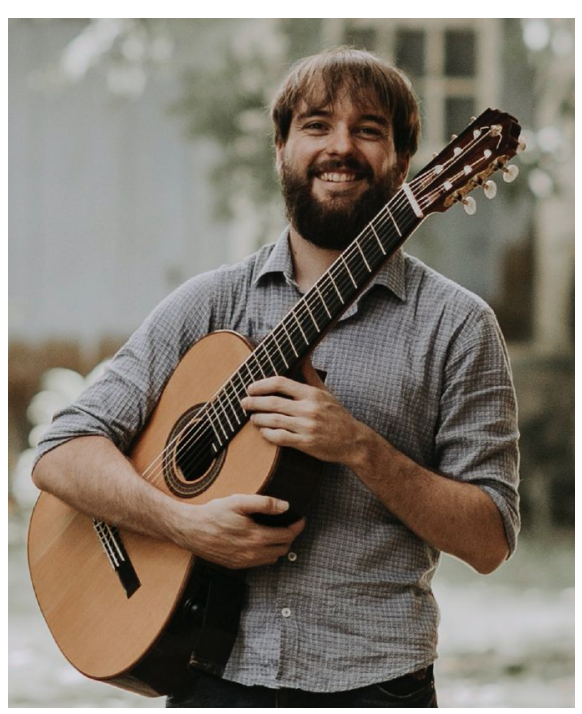

Professor Substituto do curso de Música da Universidade Federal da Integração Latino-Americana (UNILA). Bacharel em Violão Clássico pela Unicamp sob orientações de Fabio Scarduelli, Paulo Martelli e André Ribeiro, mestre em Composição Musical pela Unicamp sob orientação da Profa. Dra. Denise Hortência Lopes Garcia e doutorando em Sonologia pela USP-São Paulo sob orientação do Prof. Dr. Silvio Ferraz. Ricardo Henrique desenvolve pesquisas em música nas áreas de performance, análise, composição e pedagogia da performance musical. Como performer, atua em campos da música clássica e popular brasileira tendo realizado apresentaçôes em diversos locais como SESC Campinas, SESC Interlagos, SESI Araraquara, Circuito Cpfl Parklett Musical, Movimento Violão - Jovens Virtuoses, Simpósio Internacional da UFMG, Seminário Milton Nunes, Seminário de Violão de Rio Claro, dentre outros. Em música de câmera, conquistou os prêmios de $1^{\circ}$ lugar no Concurso Nacional Musicalis (2013); $2^{\circ}$ lugar no Concurso internacional Raul Sánchez Clagett de Violão (Uruguai, 2013) e $1^{\circ}$ lugar no Concurso de Violão Souza Lima (2017).

E-mail: ricardo-hs@usp.br

Website: linktr.ee/ricardohenrique.musica

ORCID: https://orcid.org/0000-0002-9668-1802 


\section{Canto para Hildegard}

Canto para Hildegard é uma peça escrita originalmente para violão 7 cordas com scordatura expandida. A peça foi escrita no ano de 2020 fruto de um processo composicional baseado na reescrita de fragmentos melódicos do canto gregoriano Caritas Habundat de Hildegard von Bingen. 


\section{Canto para Hildegard}
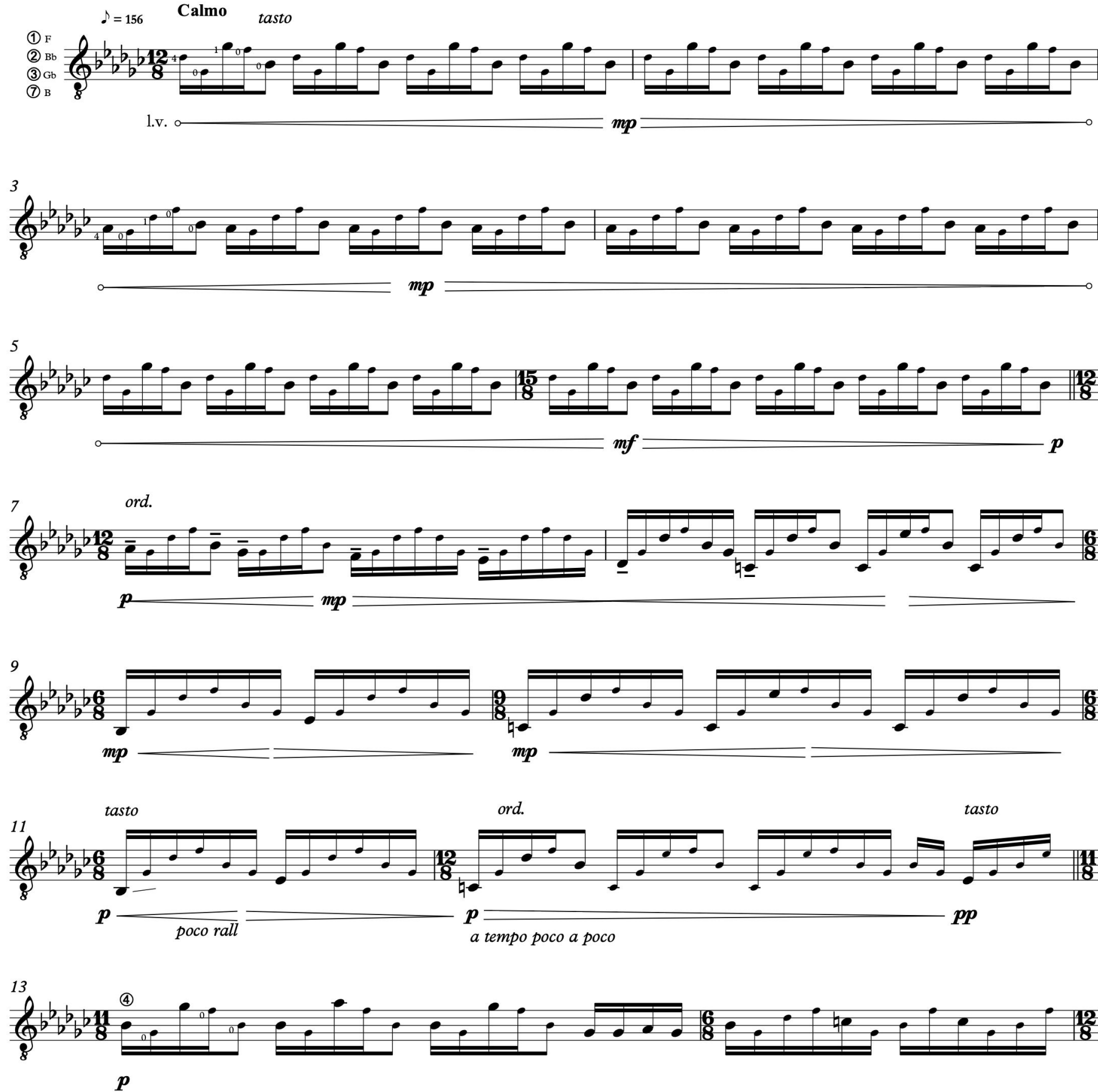

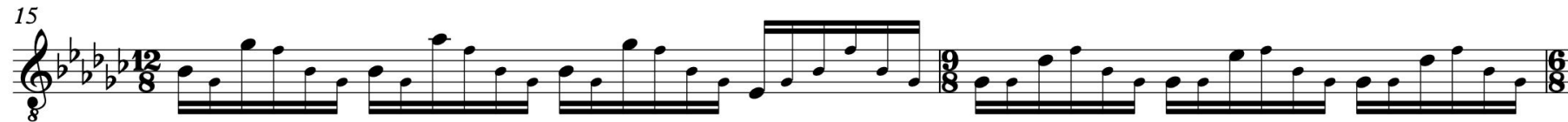

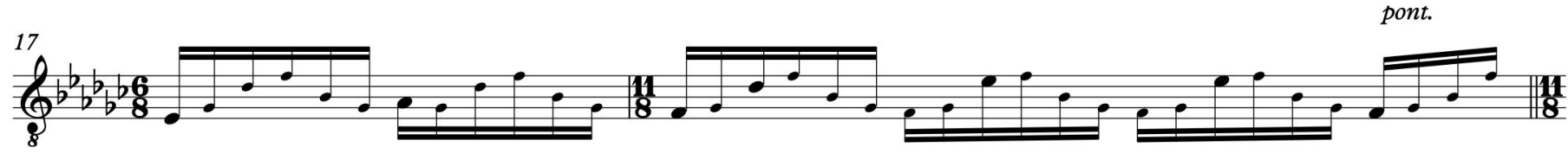




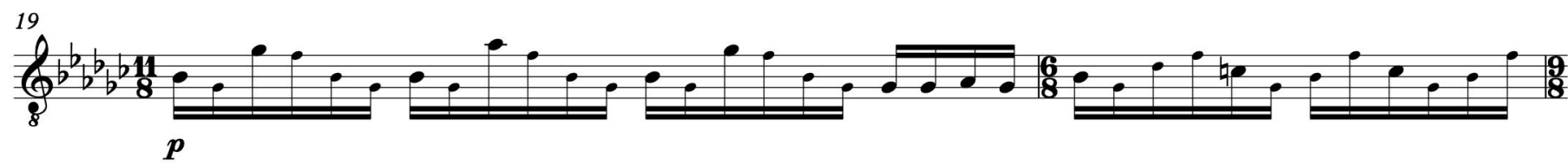

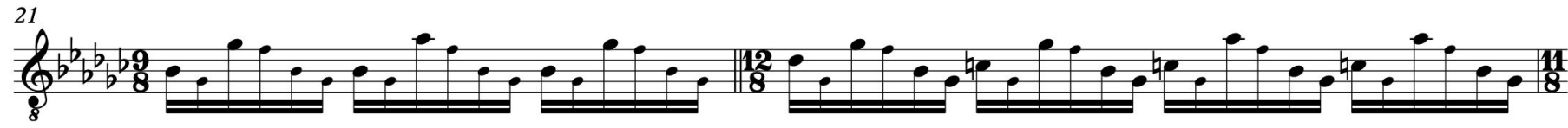

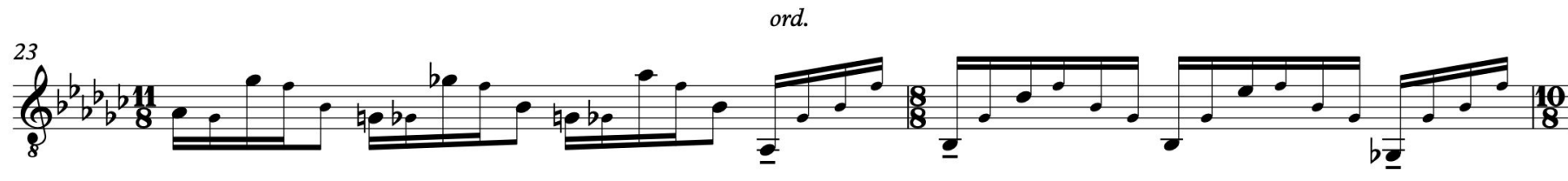

$m p$
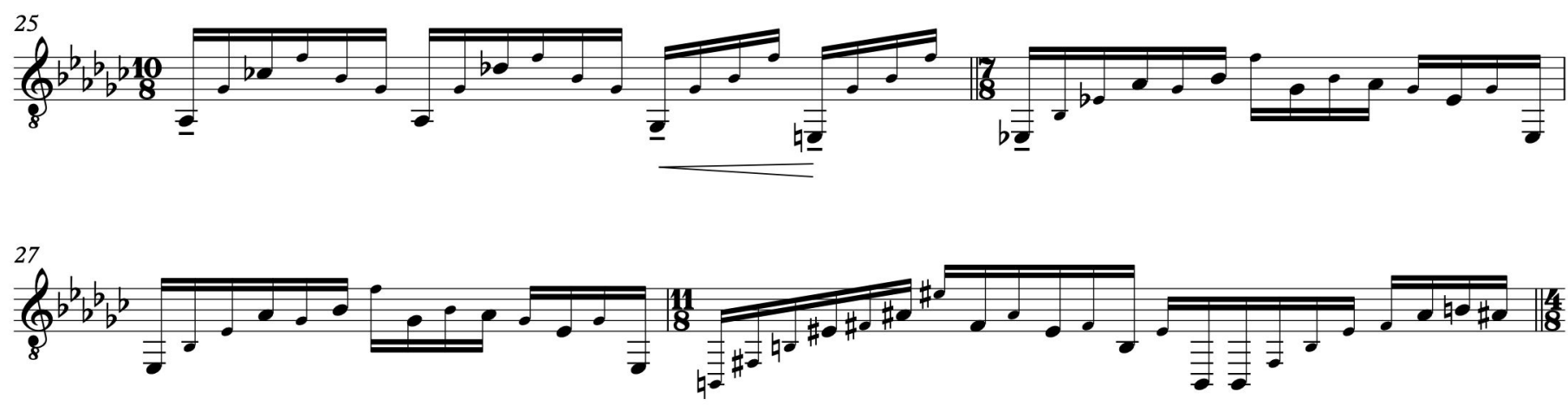
Poco meno e rubato
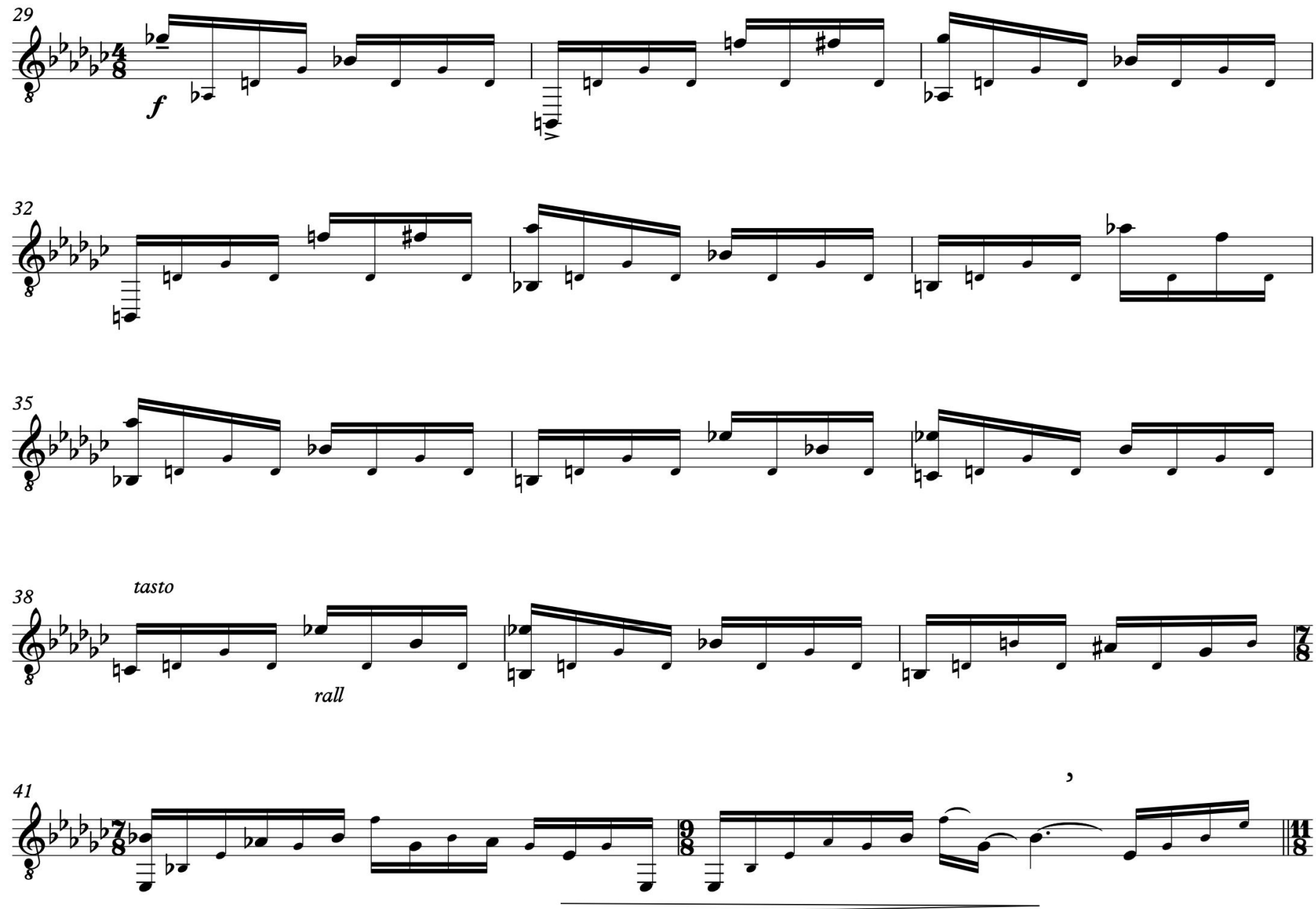


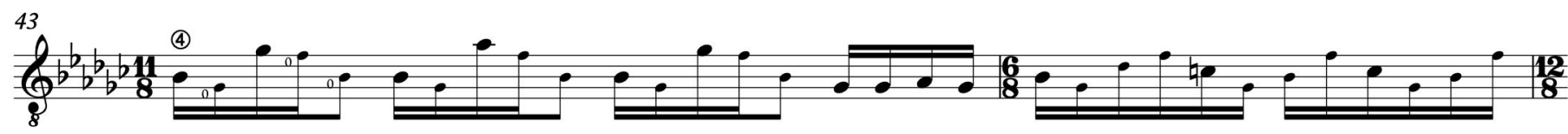

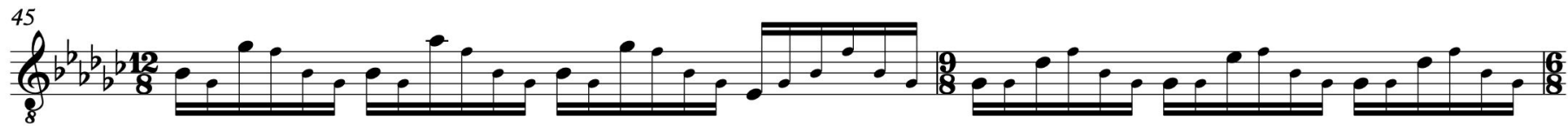

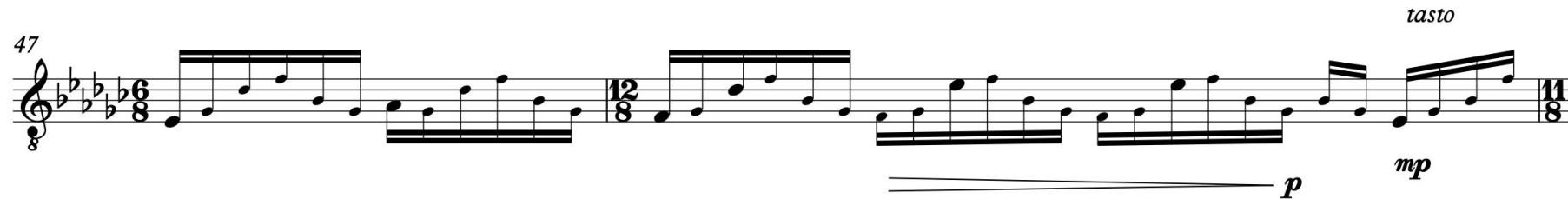

(6)

(t)

(b)

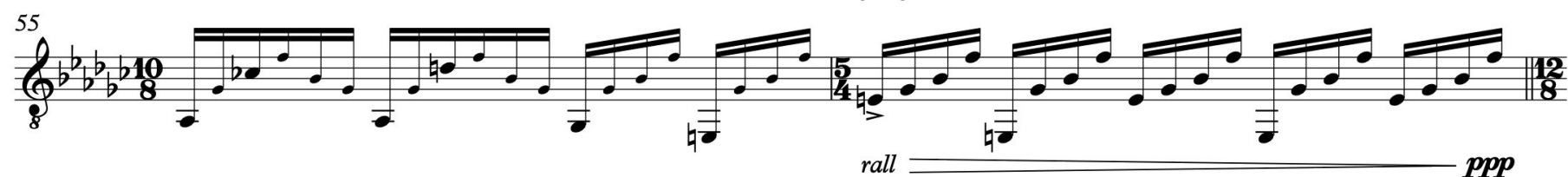

8

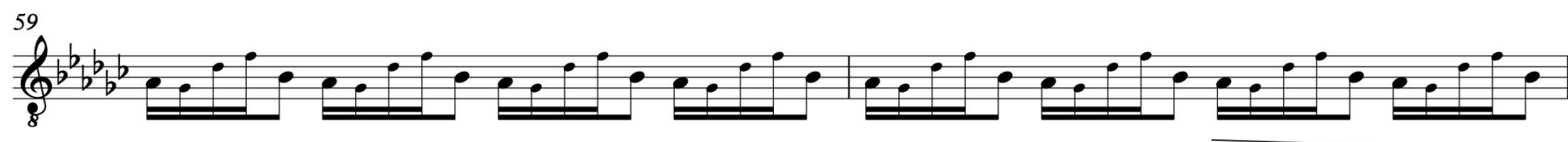

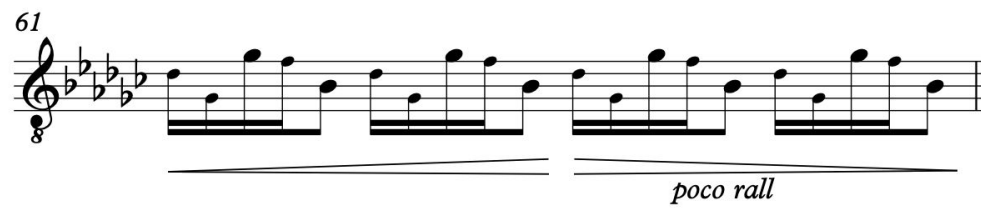

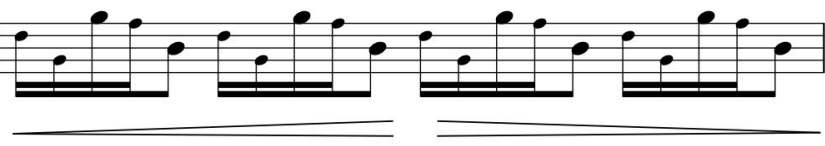

$\frac{63}{p q}$

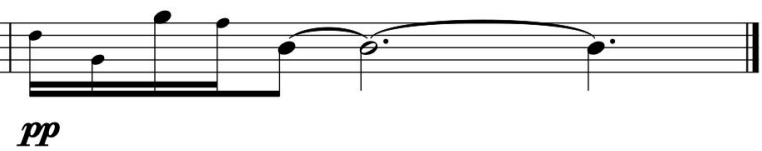

